\title{
Confronting product life thinking with product life cycle analysis
}

\author{
McAloone, Tim C.
}

Published in:

Proceedings of EcoDesign 2001: 2nd International Symposium On Environmentally Conscious Design And Inverse Manufacturing

Link to article, DOI:

$10.1109 / .2001 .992315$

Publication date:

2001

Document Version

Publisher's PDF, also known as Version of record

Link back to DTU Orbit

Citation $(A P A)$ :

McAloone, T. C. (2001). Confronting product life thinking with product life cycle analysis. In Proceedings of EcoDesign 2001: 2nd International Symposium On Environmentally Conscious Design And Inverse Manufacturing (pp. 60-64). IEEE. https://doi.org/10.1109/.2001.992315

\section{General rights}

Copyright and moral rights for the publications made accessible in the public portal are retained by the authors and/or other copyright owners and it is a condition of accessing publications that users recognise and abide by the legal requirements associated with these rights.

- Users may download and print one copy of any publication from the public portal for the purpose of private study or research.

- You may not further distribute the material or use it for any profit-making activity or commercial gain

- You may freely distribute the URL identifying the publication in the public portal 


\title{
Confronting Product Life Thinking With Product Life Cycle Analysis
}

\author{
Dr. Tim McAloone \\ Associate Professor \\ Section of Engineering Design \& Product Development \\ Department of Mechanical Engineering \\ Technical University of Denmark (DTU) \\ Building 358, Akademivej \\ 2800 Lyngby \\ Denmark \\ tim@mcaloone.com
}

\begin{abstract}
Industry is increasingly being confronted with the need to consider the whole life cycle effects of its products, in order to make environmental improvements of any significance. There is a danger that naive environmental decisions are made, due to apparent lack of data or actual lack of insight.

This paper describes a case study, where a class of students was presented with a product from the Danish company, Danfoss $A / S$, and given the task of carrying out an initial environmental evaluation of the product. This evaluation consisted of both a "life cycle check" and an exercise where the students were to "read" the environment out of the product, in order to systematically, quickly and efficiently come to some design recommendations for the company. The phrases " $L C A$ " and "product life thinking" will be described and differentiated and a pattern identified for their cooperative effect in use.
\end{abstract}

Keywords: eco-design, life cycle analysis, product life thinking.

\section{Introduction}

Good environmental design activity requires skills in both analysis and synthesis, if the problem is to both be understood and acted upon. However we can see that to date, there are very few examples of an integrated approach to eco-design [1] and one of three suboptimisation problems occur: the task either gets sent in two completely different directions to be solved, where the final synthesised result nowhere near relates to the reality of the problem, nor the recommendations of the analysis; or

the task is both analysed and synthesised by an analyst, who has deep insight into, and expertise in data modelling and manipulation, but who can only speculate about the actual realisation of design changes to the product, due to limited understanding of the product's real life; or

the task is both analysed and synthesised by a designer ('synthesiser), who has neither the time nor the expertise to go into detail with the analysis of the problem, and so must make an educated guess about the priorities of the design activity.

In any case, the final solution is all too often a disappointing compromise due to lack of resources, in one form or another.

This type of problem is not a new phenomena in product development, and our highly complex world demands great cross-functionality and multi-disciplinary work across competence boundaries, in order to achieve results of an acceptable innovation level [2].

This paper describes a case where a class of 28 students in their seventh semester (out of ten) of their Masters degree were given the opportunity to try a multidisciplinary approach to a project, the topic of which was set (and later implemented) by the Danish company, Danfoss. Our hypothesis for this study was that a multi-disciplinary 
approach to eco-design is both teachable (by staff) and learnable (by students), giving greatly enhanced effects on the final result.

\section{Research method}

The course "Sustainable Industrial Production" at DTU was a new initiative in autumn 2000, headed and coordinated by a member of staff in the Department of Manufacturing Engineering ${ }^{1}$ at DTU. The course was devised as a cross-campus collaboration, with representatives of a number of competencies, such as energy engineering, production, environmental management and product development.

There were four overall themes in the course:

1. the companys environmental policy and strategy;

2. the company's products;

3. the company's production; and

4. the companys processes.

Each of these themes was borne by a project in collaboration with an industrial company. At the end of the four themes a final project was carried out with a fifth company, this time chosen by the students themselves.

The module of the course described in this paper covered theme 2: The companys produ cts. The theme considered the environmental effects of products through product development and was comprised of two key elements:

$$
\begin{aligned}
& \text { life cycle analysis; and } \\
& \text { eco-design synthesis. }
\end{aligned}
$$

The course module was designed so to provide a real-life company-defined project as the bearing element of the module, with consultant-like lectures given to provide and supplement the students' knowledge and skills necessary to complete the task.

The 28 students were split into seven groups of four people, and were followed throughout their project, in order both to guide them and to verify our working hypothesis.

\section{The project task}

The students (mostly majoring in environmental studies, although with a small representation from manufacturing or mechanical engineering) were presented on the first day of their projects with a product from the company, Danfoss, who desired a re-design of an expansion valve,

\footnotetext{
${ }^{1}$ Acknowledgement to H. Wenzel, IPL, DTU
}

largely used in supermarket/butchers refrigerators (see Figure 1).

The expansion valve acts as a part of a larger cooling system, to regulate the amount of coolant flowing in the refrigeration system, in order to maintain a steady and reliable temperature. In itself, the expansion valve was made up largely of brass, and contained a (lesser harmful) coolant in its thermostat unit.

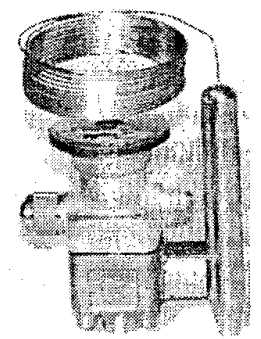

\section{Figure 1 .- Danfoss TE5 Expansion valve}

The students were asked to firstly analyse the valve and then to make actual engineering design proposals for design modification. In total four weeks (part time) were set aside for the task, and close contact was established with two lecturers and two contact people at Danfoss.

\section{A short word on LCA and product life thinking}

Life Cycle Assessment (LCA) is now an established science, and a strong body of scientists is established worldwide, to objectively:

"evaluate the environmental burdens associated with a product, process, or activity by identifying energy and materials used and wastes released to the environment, and to evaluate and implement opportunities to affect environmental improvements". [3]

Throughout the past decade this science has grown dramatically, and LCA specialists are now commonplace in almost every globally active product developmentrelated company. The task of the LCA specialist is to analyse the environmental effects related to the product, process or activity, based upon a "life cycle inventory" of the product and some knowledge of the product's activities throughout its lifetime.

Product life thinking, on the other hand has little to do with collecting and manipulating inventory figures; this technique rather focuses on the product itself, and in particular, the life it leads. By this it is meant that the product developer can already begin to anticipate the 
various life stages that the product will go through and the "meetings" that the product will have with a product life stage and a stakeholder (see Figure 2).

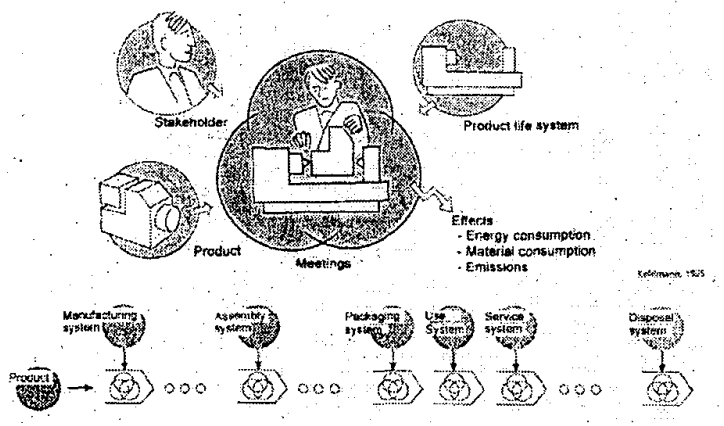

Figure 2 - The concept of meetings [4]

The above figure describes a meeting [4] between product, product life system and a stakeholder. It is only as a result of such meetings that environmental effects actually occur.

The task of product life thinking is carried out by the product developer to enable them to synthesise changes in the most relevant and important places.

\section{Co-operative effects in analysis and synthesis}

This paper builds on the hypothesis that it is important to be able to understand the nature and content of both analysis and synthesis, and to know where, when and whom should carry out both activities. In isolation, the results of a life cycle analysis give speculative suggestions about scenaria that may or may not exist in the product's lifetime, and risk being missed by the analyst. In turn, understanding the product life activities and meetings that the product has throughout its lifetime is not sufficient to be able to make certain adjustments to the design - more detail and quantification is often required.

We tested the hypothesis described in the previous paragraph by combining them in a project.

\section{Case study: ( $7 \times 4$ students $x 5$ weeks)}

The four week student project was initiated by a letter from Danfoss' Technology Manager, describing the need to carry out a redesign for environment on the expansion valve TE5 (Figure 1), together with two examples of the expansion valve per team (on having been disassembled and broken down in to material components. The students had the opportunity to pose questions to the Danfoss representative, and to establish contact with him and his department for the purposes of the project.

The students were thereafter supported by lectures on LCA and product life thinking, and were subsequently instructed to carry out both an analysis and a synthesis exercise as a bare minimum in their projects.

The LCA technique used was the Life Cycle Check (LCC) [5], which is a way of shortcutting the long and cumbersome task of carrying out a full LCA, and quickly gaining an overview of the important potential environmental effects, based on the product's own properties and a brief insight into the system in which the product operates.

The life cycle thinking technique was introduced parallel to the LCC technique, in order to aid the students when trying to "read" environment out of the product. The students were urged to carry out an exercise where they listed all the relevant life stages of the TE5 expansion valve and the relevant stakeholders. From here a series of scenaria were sketched, ensuring that the product's life was explored in detail. This type of activity initially raises more questions than it does answers, and this is where the close collaboration with Danfoss proved to be invaluable. After this stage, the LCC could be carried out according to the various scenaria.

The students had been requested both to analyse and to synthesise, and the two techniques described above, LCC and product life thinking, were key founding methods on which the students should begin to draw initial analysis conclusions and to make the first strokes of the pen under the synthesis activity.

\section{The results and their handover to Danfoss}

The final assessment of this project was an oral presentation by each team to Danfoss, assisted only by an A1-sized poster, as their presentation material. The students received comments from the tutors on their analysis achievement, synthesis achievement, and their ability to deliver a message to a company, in the form of such a presentation.

On evaluation the students' work was found to be enriched by the skills they had acquired to both make a fast analysis, but also to be able to structure a product life summation, considering the instances where the product met its stakeholders and life systems. This allowed for more focused analysis in the LCC and also a concise 
pinpointing of the high priorities for environmental design efforts.

The results from the students were compared by the author with an independently executed full LCA of the same product. Three main observations are noted:

the inventory stage of the LCC came very close to that of the independent detailed LCA, giving graphs of similar shapes;

the eco-design proposals made by the students as a result of their combined activity showed a much deeper understanding of the product as it is used (and sometimes misused) throughout its real lifetime, allowing for design proposals to be made on the strength of insight, rather than speculation;

the presentation form of an Al-sized poster forced the students into being both concise and creative with the space available to them, leading to an efficient and extremely effective communication of an otherwise complex and involved subject.

Furthermore the students' posters could be taken directly and presented within Danfoss to engineers who previously had not seen the exercise be carried out. The posters' form gave convincing proposals for eco-design, based on a method that was plain to see. Furthermore, the presence of seven posters, studying the same product and drawing very similar analysis conclusions, always helps to raise the level of confidence!

\section{Discussion of observations}

Throughout the intensive project period the students were observed for their reactions to the project and teaching styles; their ability to combine the analysis and synthesis tasks; and their final project result.

The students were very impressed with the level of contact and commitment shown by Danfoss, which had an obvious positive effect upon their motivation to work on a real life problem, which was requested based upon real life needs. The lectures given to the students underway in their projects were structured and timed more to resemble consultancy training than a traditional sit-and- listen lecture. This means that the lectures were directly related to, and directly helped the students with their project work, by giving them enabling tools and methods that they needed immediately.

Although the majority of the students on the course were analysts by nature and by study-background, they managed to reach such a level of aptitude with the early stages of synthesis that Danfoss found their suggestions useful and directly applicable. A group of 25 Danfoss engineers were presented by the author with a structured brainstorm that was carried out by the students, looking at the expansion valve's life stages and the meetings throughout its life and asking questions related to these meetings. The value of the method could be directly understood by Danfoss, who were impressed by the depth and completeness of product life thinking that the students had reached in such a short time, with so little previous knowledge of the product/company activities and methods.

Although the students had worked intensively in their groups of four, the results of all the groups'LCC analyses showed up as being very similar to each other. The stakeholder analysis and product meetings exercises showed to give good foundation for pinpointing areas where the product should be improved environmentally, based upon structured brainstorming, dialogue with Danfoss and relation of the product to its real life.

\section{Conclusions}

The main hypothesis for this study was that a multidisciplinary approach to eco-design is both teachable (by staff) and learnable (by students), giving greatly enhanced effects on the final result.

It can be concluded that there is an opportunity to more closely relate the analysis and synthesis parts of ecodesign, and that there are relatively simple methods that can assist in this relation, giving fruitful results in projects.

A shortcut LAC method (the LCC) proved useful in this type of activity, giving the opportunity to quickly make priorities and then move on to the synthesis activity.

A carefully planned blend of analysis and synthesis (and the respective supporting methods) leads to deeper understanding of the product in a whole-life context. This ensures that synthesis proposals are based upon insight rather than speculation.

Large reports are not always the answer! Fitting the project reporting style to the needs of a busy company with little depth of knowledge of LCA techniques (at least within the product development department) gives great advantages, in so much that it forces clear and concise reporting to be carried out.

The students reacted positively to the teaching style and showed an interest in applying the methods they had learned. 
A secondary effect was also seen, inside Danfoss, who could directly use the results from the posters presented to them, and the method which they had explained to them.

\section{References}

[1] McAloone, T. C. (2000) Where is Eco-Design Going?, in Proceedings of Joint International Congress and Exhibition, Electronics Goes Green 2000+, Berlin, Germany.

[2] McAloone, T.C. \& Andreasen, M. M. (2001) Joining Three Heads: Experiences from Mechatronic Projects, 12 Symposium, Fertigungsgerechtes Konstruieren 01, $\mathrm{H}$. Meerkamm (Hrsg.), Friedrich-Alexander-
Universität Erlangen-Nürnberg, Germany.

[3] SETAC (1990) A Technical Framework For Life-Cycle Assessment: Workshop Report, A Technical Framework For Life-Cycle Assessments, Society of Environmental Toxicology and Chemistry (SETAC), Washington DC.

[4] Keldmann Hansen, T. (1997) Improved Environmental Performance through Product Development, $\mathrm{PhD}$ Thesis, Department of Control \& Engineering Design, Technical University of Denmark.

[5] Wenzel, H., Caspersen, N., Schmidt, A. \& Hauschild, M. (2001) Product Life Cycle Check, First draft, IPU, DTU, Danmark. 